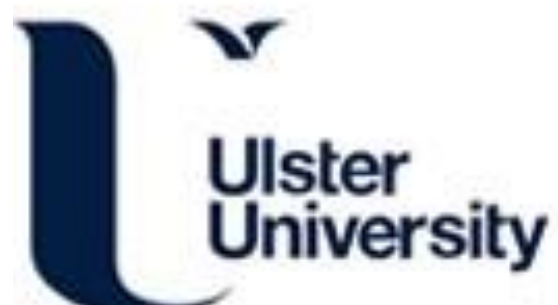

\section{Evacuation response behaviour in unannounced evacuation of licensed premises}

Boyce, K., McConnell, N., \& Shields, J. (2017). Evacuation response behaviour in unannounced evacuation of licensed premises. Fire and Materials, 41(5), 454-466. https://doi.org/10.1002/fam.2430

Link to publication record in Ulster University Research Portal

\section{Published in:}

Fire and Materials

Publication Status:

Published (in print/issue): 22/08/2017

DOI:

10.1002/fam. 2430

\section{Document Version}

Author Accepted version

\section{General rights}

Copyright for the publications made accessible via Ulster University's Research Portal is retained by the author(s) and / or other copyright owners and it is a condition of accessing these publications that users recognise and abide by the legal requirements associated with these rights.

\section{Take down policy}

The Research Portal is Ulster University's institutional repository that provides access to Ulster's research outputs. Every effort has been made to ensure that content in the Research Portal does not infringe any person's rights, or applicable UK laws. If you discover content in the Research Portal that you believe breaches copyright or violates any law, please contact pure-support@ulster.ac.uk. 


\section{FIRE AND MATERIN LS}

\section{EVACUATION RESPONSE BEHAVIOUR IN UNANNOUNCED EVACUATION OF LICENSED PREMISES}

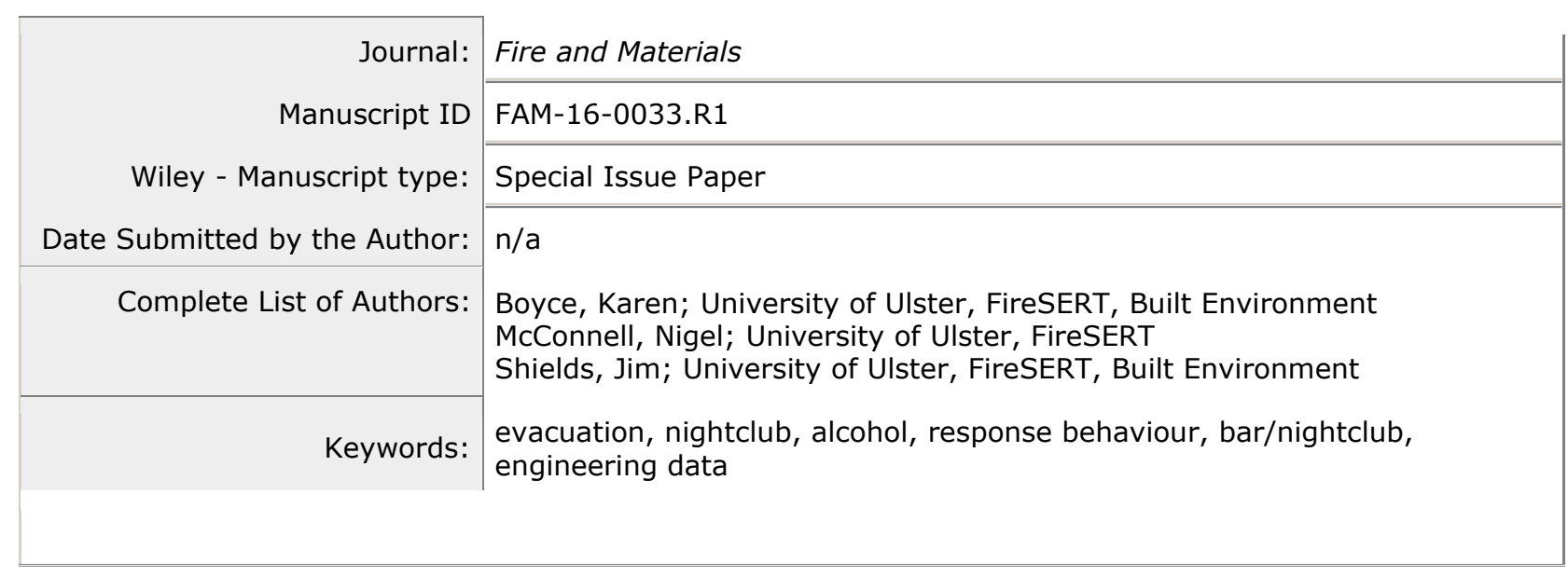

SCHOLARONE ${ }^{\text {IM }}$

Manuscripts 


\begin{abstract}
An understanding of the behaviour of individuals and groups during evacuation is key to the development of evacuation scenarios as part of an engineering design solution. Furthermore, it is important that engineers have reliable and accurate data on pre-evacuation times and movement for use in time based evacuation analysis. This paper presents, for the first time in the published literature, a detailed analysis of an unannounced evacuation of licensed premises and provides important data and understanding regarding behaviour for use in fire safety engineering design and evacuation modelling. Findings on recognition times, response behaviours, pre-evacuation times and final exit flows for a function room and lounge bar in the licenced property are provided. The results suggest that the evacuation time in the lounge bar was characterised by generally longer pre-evacuation times and relatively shorter movement times, whereas the evacuation time in the more densely populated function room was characterised by shorter pre-evacuation times but extended flow times. The paper highlights important design and management issues with respect to the evacuation of persons under the influence of alcohol and considers the impact of staff intervention through directed voice communications. The variation in response behaviours between the two separate areas of the premises are highlighted and discussed.
\end{abstract}

KEY WORDS: $\quad$ unannounced evacuation, bar, nightclub, alcohol, response behaviour, pre-evacuation time, engineering data

\title{
INTRODUCTION
}

Licensed premises (including pubs, clubs and entertainment venues) can cause particular concern with regards to evacuation, not least because of the nature of the occupants (potentially high numbers, consumption of alcohol, and unfamiliarity with the premises or evacuation procedures) and the nature of the environment (often low lighting, high noise levels (music) and variation in floor levels). People attend bars, clubs and entertainment venues to enjoy themselves, i.e. to have something to eat or drink, dance, listen to music or watch a show; often they have paid entry to the premises and it is important to understand what impact this may have on their willingness to respond and the appropriateness of their response to an alarm or other fire cue. Unfortunately, there have been many examples of large life loss in such premises; some notable historical incidents include Cocoanut Grove (1942, 492 deaths) [1], Beverley Hills supper Club 1977, 165 deaths [2], Stardust Fire Dublin,1981, 48 deaths [3] and serious nightclub fires are still occurring in modern times. More recent examples are the Lame Horse Fire, Russia, 2009 (156 deaths) [4], the Station Nightclub fire, Rhode Island, USA, 2003 (100 deaths) [5, 6], and the Kiss Nightclub fire in Santa Maria, Brazil, 2013 (242 deaths) [7]. Many of these events were characterised by overcrowding [1,3,5,6,7], insufficient exit capacity [6,7], blocked/locked escape routes [3], 
ignition often by pyrotechnics $[3,5,6,7]$ and very rapid fire growth due to flammable materials in the contents [1] or wall/ceiling linings (often used as soundproofing) $[3,5,6,7]$.

Our current understanding of evacuation behaviour in such premises has come almost entirely from official government investigations or independent research investigations of the circumstances surrounding major fires such as those referred to above, with perhaps the Beverly Hills Supper Club [8,9,10] and the Station Nightclub [11,12] fire being those most thoroughly investigated to date. Much of the research has indicated that behaviour in such premises is similar to that in other premises. For example, Aguirre et al [11], examining 406 witness statements and newspaper articles of the Station Nightclub fire, determined that the majority of persons engaged in normative behaviour characterised by helping others and looking for other group members. Johnson [8], investigating the Beverly Hills Supper Club fire, also concluded that emergency egress was characterised by social order and that social norms, values and affiliations prevented 'ruthless competition for exits' despite dwindling escape route options. Analysis of the occupant profiles in the Station Nightclub fire by

Aguirre et al [11] and Fahy et al [12] highlighted the tendency for people to visit in groups as an important characteristic of such premises; according to Aguirre et al [11] this was in the region of $90 \%$. Importantly, Aguirre et al [11] also found a positive association between size of group and the chance of injury in this fire and this relationship between size of group and chance of injury was also suggested by Feinberg et al [9] in their analysis of the Beverly Hills Supper Club where they concluded that people put themselves in great danger whilst assisting others in their groups and staff performed heroic acts whilst assisting patrons. Exit usage in the Station Nightclub was investigated by Fahy et al [11] who concluded that more than half of the survivors attempted to use their familiar route (the front door) to exit. Given the locations, however, of the majority of the victims, i.e., in and around the entrance, it would seem that they too had headed towards their closest and most familiar route.

Despite an understanding that social norms prevailed in these fires and some understanding of exit choice behaviour, to date there has been limited understanding of individual response behaviour and, in particular, pre-evacuation times and movement times [13] in licensed premises. Understanding of individual pre-evacuation times is limited to that which can be gleaned from video evidence of the Station Nightclub fire; those watching the band on stage recognised the rapidly developing fire quickly (at about 19 seconds) and most had started to evacuate within 30 seconds and indeed before the alarm had activated. In the Beverly Hills Supper club fire there was reported to be a 21 minute delay between the fire first being discovered by a member of staff in the Zebra Room and the majority of patrons being notified (in the Cabaret Room) but nothing is known about the individual times to start to move once they were made aware of the need to evacuate.

The components of the engineering timeline i.e. pre-movement and movement time [13], are essential for engineering design and computational modelling, yet in the chapter "Engineering Data" in the latest edition of the Society of Fire Protection Engineers Handbook of Fire Safety Engineering [14] data on publics houses, nightclubs and other licensed premises was notable by its absence. In this study, i.e. a video-taped, unannounced evacuation of licensed premises, the authors attempted to provide data with respect to evacuation response behaviour and flows in such premises and thus start to redress the scarcity of data and understanding in this area.

\section{METHODOLOGY}


The unannounced evacuation took place in a single storey building, of approximately $250 \mathrm{~m}^{2}$ [15]. It comprised three distinct, interconnected areas, Figure 1, all accessed from the front of the building directly off the main street:

- Lounge Bar - this area covers $70 \mathrm{~m}^{2}$ and provides the main access to the entire building. The lounge area has fixed seating and a small entertainment area to the rear. Adjacent to the lounge area to the left are female toilets. To the right is access into a link corridor $(9 \mathrm{~m}$ length, $1 \mathrm{~m}$ width) which connects to the front public bar and the rear function room.

- Function Room - this area covers $75 \mathrm{~m}^{2}$ and is accessible from the linked corridor from the lounge bar. It comprises mostly dance floor area with a bar to one end. Seating is confined to a few raised areas, one of which houses the DJ kiosk. There is a short exit corridor of $1.2 \mathrm{~m}$ width leading via double doors directly to the outside yard and a single exit leading to the link corridor. The yard at the rear is positioned at a height of $2.0 \mathrm{~m}$ above the floor level of the building and is accessible via a set of steps almost directly adjacent to the rear exit doors.

- a Public Bar $\left(28 \mathrm{~m}^{2}\right)$ with pool table with direct access from the street until $6 \mathrm{pm}$ and accessed via the Lounge bar thereafter.

The bar was popular with teenagers and young people in the local area and most would be expected to be regulars and familiar with their surroundings. At the time of the evacuation it had an Entertainment's License from the local council for an occupancy of 305 persons (125 in the lounge bar, 120 in function room and 60 in public bar). The alarm was a siren, activated using a break glass unit.

Previous discussions with the bar owner revealed that the building had been evacuated on a number of occasions prior to the unannounced evacuation due to deliberate and malicious activation of the alarm via the break glass unit.

\section{Preparations for the Evacuation}

Some weeks prior to the evacuation, the permission of the bar owner was sought and obtained. As additional precautions the police and the fire service were notified and were to be informed throughout the event; a trained first aider was also on site. The evacuation was recorded using eight fixed video cameras which were installed and concealed in the days prior to the evacuation when no staff were on duty and then turned on early in the evening of the evacuation in the absence of staff and prior to patrons being present. The cameras were positioned so as to capture response behaviours, crowd movement in and between the areas of the bar and flow through the final exits. The positioning of seven video cameras covering the function room, lounge bar, and linking corridor is shown in Figure 1. One camera, located in the public bar failed to operate and hence that area is excluded from the analysis presented here. Flood lights $(150 \mathrm{~W})$ were installed at camera positions 2 and 5 due to the low ambient lighting in the building to ensure response behaviour of occupants could be recorded. These were wired to coincide with activation of the alarm.

\section{The Evacuation}

The evacuation was initiated on a Sunday in February at $12.15 \mathrm{am}$. Only the bar owner and the bar manager had prior knowledge of the evacuation and, in this respect, it was unannounced for both the patrons and the small live band that was playing at that time. At 12.15 am the bar manager triggered the alarm (a siren) from the control panel and the 
evacuation of the premises commenced. Doormen opened the exits and assisted with the evacuation of the premises. The alarm continued to sound throughout the evacuation of all areas.

At the time of the alarm, 239 persons occupied the building. A breakdown of occupants in each of the locations by sex is given in Table 1 together with the evacuation times from each area. As noted previously, the camera in the public bar failed to operate and so the numbers and evacuation time for the public bar is an estimate made by the bar manager.

At the time of the evacuation there were approximately 152 persons in the function room, 72 people in the lounge bar and approximately 15 people in the public bar. The function room occupancy was above the legal occupancy limit of 120 persons, whilst the lounge bar and public bar were both well below the legal limits of 120 and 60 respectively.

\section{Data Analyses}

The evacuation behaviour of occupants of the lounge bar and the function room was determined through analysis of the videos (location shown in Figure 1.)

One of the key components of an engineering analysis is the determination of the preevacuation time. The pre-evacuation time (also referred to in literature as pre-movement time [13], delay time, start-up time, pre-egress activity time) has been defined ${ }^{13}$ as "the interval between the time at which a general alarm signal or warning is given and the time at which the first deliberate evacuation movement is made". The pre-evacuation time was therefore of interest in this study together with its two components namely, the recognition time and response time which have been defined [13] as:

- Recognition time $\left(t_{\text {rec }}\right)$ - time after an alarm has sounded or other fire cues are apparent up to the time the occupants realise there is an emergency and begin to respond - this is the time taken to recognise that the cues that they have been subjected to indicate that something unusual is happening and the time to interpret that information and decide how to respond

- Response time $\left(t_{\text {res }}\right)$ - the interval between recognition time and the time at which the first move is made to evacuate the building. This time is the time taken to perform activities and may or may not involve movement such as investigating, warning others, searching for friends/family, retrieving personal belongings etc. It could also involve re-engaging in activities being undertaken prior to the alarm.

The difficulty associated with breaking down the pre-evacuation time into the recognition and response times has been recognised previously [16]. This difficulty stems from the fact that it is impossible to interpret the end point of the recognition time which in fact is a cognitive process engaged in by the individual. Whilst recognition time as defined thus is impossible to precisely determine, close inspection of the videos in this study suggested that some individuals did show early indications that they had heard the alarm. The point at which noticeable reactions were evident, eg looking around for information or disengaging from prior activity (even if only momentarily) was therefore used in this analysis to signal the end of the recognition period and the beginning of the response period allowing both recognition time and response time to be determined. 
Also important to our understanding of response behaviour are the activities that individuals engaged in prior to evacuating and therefore this analysis also explored the time (from alarm) at which individuals physically disengaged from their pre-alarm activity and engaged in other activities prior to initiating their final approach to an exit. This time is referred to here as 'time to start activity' and is equivalent to the start of the 'activity stage' defined previously by Galea et al [16].

Initial observation of the videos suggested that the evacuation of the lounge bar was characterised by a wide variation in and delayed reaction to the alarm with almost all occupants choosing to leave by the main entrance and little sustained flow at the exit. The analysis of the lounge bar, therefore, focussed solely on the pre-evacuation time period and the activities of occupants during that time. All analysis was conducted initially by one researcher and cross checked by a second. The first researcher provided a detailed description of each individual (gender, dress), their location within the space, whether they were alone or with others. The videos were time-stamped from the moment the alarm sounded and researchers were able to move through frame by frame to determine associated recognition times, response times, activity times and pre-evacuation times (as defined above). The detailed descriptions of the individuals allowed detailed cross-checking by the second researcher and were essential to facilitate tracking of individuals across cameras, which was often necessary as individuals moved about in the space prior to evacuating.

The same approach was adopted with respect to the analysis of the function room. The camera coverage in the function room and relatively low lighting levels in the seated areas limited the analysis of the pre-evacuation activity in these areas. Initial observation of the videos revealed that the evacuation of the function room was characterised by an extended evacuation time with long queues forming at the final exit. The analysis of the function room, therefore, extended to consider the flow through the final exit and understanding the reasons for the extended flow times.

It is important to note that recognition, response, activity and pre-evacuation times in both spaces were only determined for those individuals for whom response behaviours and related times could be derived with confidence. The analysis of the videos was constrained in some cases by lighting levels and the orientation of the individuals relative to the cameras. In the function room, in particular, lighting levels were low and most occupants were positioned with their backs to the cameras as they left the building. In a number of instances, although attempts were made to track individuals across cameras, inevitably facets of their response behaviour could not be established. These limitations to the analyses are reflected here through different sample sizes for eg pre-evacuation time and time to start activity within each area.

\section{RESULTS- LOUNGE BAR}

As noted above, the occupancy of the lounge bar at the time of the alarm was 72 , giving a density of $0.95 \mathrm{~m}^{2} /$ person. The evacuation time for the 72 persons from the lounge bar was 3 minutes and 19 seconds. When the alarm sounded, the majority of the occupants were either standing or sitting in groups.

At the time of the alarm, a live band was playing in the lounge but they ceased playing almost immediately. Forty-two seconds after the initial sounding of the alarm, the bar manager made an announcement from behind the bar using a public announcement system asking occupants 
to evacuate: "Well ladies and gentlemen, I have just been informed that the fire alarm has gone off and for safety reasons I'd like everyone to vacate the premises [at 49 secs] as quickly and quietly as possible, so for safety reasons as quickly and quietly as possible. I don't know what the problem is but we will try and get it sorted out'. The duration of this message was 18 seconds. In addition to this announcement there were additional isolated cases of staff requesting occupants to evacuate from the building. The most notable of these being by a doorman located at the main exit who at 22 seconds announced "right folks, can you please leave the bar, please clear the bar, please clear the bar" (duration approximately 7 seconds) and made a similar announcement coinciding with the bar manger's public announcement at 42 seconds.

\section{Recognition, Response and Pre-Evacuation Time}

The recognition time (time from alarm to noticeable reaction) was determined for 24 occupants of the lounge bar whose initial reaction could be identified from the video footage. For 21 occupants $(87.5 \%)$ recognition was deemed to be within the first 5 seconds following the alarm. It is possible that the turning on of the light in the lounge (which coincided with the alarm) precipitated these low recognition times. The remaining 3 occupants' recognition times were 10 seconds, 16 seconds and 33 seconds. The two occupants with the highest recognition times had formed a social group close to the main exit. This group was so engrossed in conversation that they exhibited no reaction whatsoever to the alarm until after another member of their group made them aware of the need to evacuate after hearing the doorman's instruction to evacuate.

The response time (from point of recognition to movement towards the exit) could be determined for 23 of the 24 occupants for whom recognition time could be determined. It was not possible to determine the response time for one occupant for whom recognition time could be determined. This occupant was a female and was last heard saying that she was going to fetch her coat. The cameras tracked her moving towards the seating area in the lounge where she went out of camera view and could not be identified again at the point of starting her exit. The mean response time of the 23 occupants was 87.4 seconds (s.d: 41.8 seconds, range: 19-168 seconds). All but one of these occupants (a lone male standing at the bar) were talking in their respective social groups when the alarm was activated.

The pre-evacuation time, i.e. the time from alarm until initiation of final movement towards an exit, could be determined with confidence for 39 persons and ranged from 33 to 172 seconds ( $\mathrm{n}=39$, mean: 84.9 seconds, median: 76 seconds, s.d: 35.8 seconds). The preevacuation time distribution for the lounge occupants is shown in Figure 2. Figure 2 indicates that the majority of occupants $(n=25,64.1 \%)$ made their final movement towards the exit between 41 and 80 seconds. Overall, $82.1 \%(n=32)$ of occupants had initiated movement towards an exit prior to 99 seconds after the alarm, i.e. 57 seconds after the commencement of the bar manager's announcement.

\section{Pre-Evacuation Activities}

The time to start activity could be established for 40 occupants, and the distribution of times to start activity is shown in Figure 3. It is noticeable, Figure 3, that only 8 occupants $(20 \%)$ had disengaged from their prior activities within 40 seconds following the alarm. Also interesting is the marked effect of the announcement made by the bar manager (via the PA system) at 42 seconds. As Figure 3 shows, seventeen (42.5\%) occupants disengaged from 
their pre-alarm activities whilst the announcement was being made. Further analysis indicates that, of these, $58.8 \%(\mathrm{n}=10)$ disengaged from their pre-alarm activities after the words 'vacate the premises' (at 49 seconds).

Figure 3 indicates that a number of individuals $(n=3,7.5 \%)$ did not disengage from their prealarm activities until 101-120 seconds. Two of these individuals, who were male and in the same social group, continued to chat and drink until 117 seconds after the alarm, despite a number of notifications in the interim. The first notification was at 16 seconds as a female in their company indicated that the doorman was opening the front door for evacuation. The second notification was the announcement by the bar manager (42 seconds) during which the men continued to simply observe other occupants preparing to evacuate. The female that made the initial notification to them got up from her seat at 62 seconds and pointed towards the bar. One of the men responded by shaking his head; this resulted in the female sitting back down. At 86 seconds the female stood up, handed her friend a coat and headed out of shot; it is possible, but not confirmed that she went to the bathroom. The men finally decided to leave when a member of staff (at 117 seconds) encouraged one of the men to leave by softly attempting to move him by the arm.

Error! Reference source not found. displays the activities undertaken by occupants during the pre-evacuation stage that led to delayed evacuation. Not surprisingly, activities such as collecting belongings and putting on over garments rated high in pre-evacuation activities. An interesting finding is that out of the $30 \%$ of the sample $(n=12)$ who collected belongings, $25 \%(n=3)$ collected items for others and $25 \%(n=3)$ returned to their initial locations to retrieve items. In addition, $22.5 \%(\mathrm{n}=9)$ of occupants delayed their evacuation as they

returned to drink and in two cases it was clear that the occupants were intent on finishing their drink prior to evacuating the building. Other less frequent activities included visiting the toilet $(10 \%, n=4)$ and moving to instruct others to leave $(5 \%, n=2)$. Three of the four who visited the toilet were female and the duration of this activity was on average 92.3 seconds with a range of $70-110$ seconds.

The times to complete these pre-evacuation activities, i.e, the period from disengaging from pre-alarm activity and final movement towards the exit ranged from 0 to 110 seconds (mean: 30.1 seconds, median: 19 seconds, s.d: 29.2 seconds). Five occupants having disengaged from pre-alarm activity made their way directly to the exit without undertaking any other activities.

\section{RESULTS - FUNCTION ROOM}

152 persons occupied the function room at the time the alarm was sounded (approximate density of $0.49 \mathrm{~m}^{2} /$ person). It is estimated that 10 persons were standing in the short corridor leading from the dance floor to the final exit (Exit 1, Figure1), 63 persons were standing/dancing in the central area of the function room close to the DJ and bar area but also in close proximity to the exits with the remainder $(n=79)$ standing/seated in the slightly elevated seating areas Figure 1. The evacuation of the function room occupants took 6 minutes and 34 seconds.

Seven seconds after the alarm had sounded, the DJ stopped the music and made the following announcement through the speakers "Ok folks, could you please leave the building by the back fire exit quickly and calmly, thank you" (duration approximately 4 seconds). In the first minute following the alarm the DJ twice asked the occupants to leave, directly them as to 
which exit to use and to not take coats or bags eg at 24 seconds "please evacuate the building by the back fire exit quickly and calmly, no coats, no bags, please move outside" and repeatedly urged patrons to leave the building.

Although the function room had two exits it was protocol for the staff to evacuate the premises directly to the outside (via Exit 1, Figure 1) rather than have them pass through the other occupied areas of the building to escape. Twelve seconds after the alarm sounded a member of staff opened the double exit doors to Exit 1 (Figure 1) and exited to the rear of the building, followed by another member of staff. One of them returned at 42 seconds and was seen to instruct occupants to leave. In the interim, a doorman positioned himself at Exit 2, Figure 1, and prevented occupants from evacuating in that direction; in essence creating circumstances akin to a situation where the main access route for occupants was blocked by fire.

\section{Pre-Evacuation Activities}

It is interesting to consider and compare the initial responses of occupants who were densely packed in the vicinity of the exit on the dance floor/bar area and those who were in other areas of the function room.

It is clear from the video that the majority $(\mathrm{n}=53,72 \%)$ of those initially on the dance floor and adjacent to the emergency exit remained in position, essentially forming part of the queue to evacuate. It is likely that the timely and repeated instructions of the DJ to evacuate via the back fire exit (Exit 1) may have had an influence in this respect, but it also possible that the high densities in the area may have encouraged/forced them to remain in place. For example, in the early stages, a few occupants close to the emergency exit were observed trying to turn around and leave the area but found it difficult to do so because of the high densities and simply gave up and stood in the direction of the exit waiting to leave. Despite the cessation of the music and two announcements by the DJ in the interim, occupants did not actually start to leave until 42 seconds following the alarm when they received the go ahead from another staff member who had previously exited via the emergency exit.

Some of the occupants $(n=20,28 \%)$ initially located on the dance floor/bar area but nearer the back of the crowd and further from the exit, left the dance floor to undertake pre-evacuation activities before re-joining the queue. The majority of those leaving the dance floor $(55 \%$, $\mathrm{n}=11$ ) did so almost immediately following the alarm (within the first 20 seconds). The mean time to complete pre-evacuation activities was 40.0 seconds (range $20-110$ seconds, s.d = 27.9 seconds). For the majority $(81.5 \%, n=9)$ it was evident that they left with the intention of collecting belongings, including coats which they put on prior to evacuating. The activity of collecting belongings (from the time they were observed starting to leave the dance floor until they were observed joining the queue once again) took on average 50 seconds (range 20106 seconds). The longest time was spent by a male who took 106 seconds to collect his own coat and returned to collect the coats of others before evacuating himself. Whilst the majority of those who were observed leaving the dance floor did so almost immediately following the alarm, others were observed to leave at later stages, i.e. between 50 and 79 seconds. It is not possible to determine from the videos what their actions were or why they disengaged at this time but there was certainly some evidence that they were seeking friends as they often entered the flow again whilst conversing with others. The relatively long queue to evacuate (discussed below) may have precipitated this behaviour in this situation. The average time from leaving the dance floor to returning to the evacuation flow for the later leaving occupants was 23 seconds (range 8-45 seconds). The longest time in pre-evacuation activities 
was spent by a male, who started to leave the dance floor 16 seconds after the alarm had sounded and did not return until 126 seconds. It is not clear what he did during this period but it was apparent from the videos that he was under the influence of alcohol.

All occupants in the seating area A (Figure 1) $(n=11)$ demonstrated a visible response to cues (alarm and announcement by DJ) within the first 20 seconds. One male immediately started to evacuate, but for the others, their subsequent response was to look around, continue to chat and drink before starting their evacuation some time later. Seven of the occupants remained in their initial location until they started their evacuation, but 3 others moved down from the seating area towards the evacuating crowd and continued to chat to and/or observe others before joining the queue and beginning their evacuation. One other (a female), left the area almost immediately and was picked up joining the queue 45 seconds after the alarm; her actions in the interim are unknown. There was evidence of about half of the occupants

(mostly female) picking up belongings (coats) prior to leaving and one instance of a female putting on her coat before leaving (an activity which took 11 seconds). The mean time spent in pre-evacuation activities for seated occupants was 30.6 seconds (range 1-115 seconds s.d. $=$ 32.3 seconds). The longest time spent in pre-evacuation activities was by a female who was seated at the front of the seating area adjacent to the dance floor. She reacted initially to the alarm at 20 seconds but in the time period until she started to leave she responded to a number of requests from others on the dance floor to get their belongings, handing them coats and drinks coat before eventually rising with her own and moving out of the area. She then returned to retrieve another coat for a male (73 seconds) and continued to converse with friends, leaving a coat back on a table before eventually starting her evacuation at 135 seconds. In total her pre-evacuation activities took 115 seconds.

\section{Pre-Evacuation Times}

The pre-evacuation time for those individuals $(n=20)$ who initially left the dance floor and those individuals in the seated area $(n=11)$ could be determined with some confidence. The mean pre-evacuation time of those who initially left the dance floor to engage in preevacuation activities was 73.6 seconds (range 36-126 seconds, s.d 26.0). The mean preevacuation time for the occupants of the seating area was 48.9 secs (range 17-135 secs, s.d $32.3 \mathrm{secs}$ ). The longer mean pre-evacuation time for those in the standing area can be explained by both the initial delay for some in making the decision to leave the queuing area and the longer time spent returning to their seats, retrieving coats etc having made the decision to do so.

The positioning of the cameras and the low lighting prevented the determination of preevacuation time for occupants in other seated areas and, as previously discussed, it is not possible to determine the point at which all those who remained on the dance floor/bar area in the queue to the emergency exit had willingly initiated movement towards the exit.

Notwithstanding, it is possible to derive a pre-evacuation time distribution for all occupants by making the assumption that the time at which each person joined the queue at the emergency exit can be used as an estimate of the pre-evacuation time. It is recognised that for those originally located in the queuing area near the emergency exit, the distinction between pre-evacuation time and travel time somewhat breaks down. Using the time at which occupants remained/joined the queue as an estimate of pre-evacuation time may result in an underestimation of pre-evacuation time for those some occupants. i. e. despite the fact that they did not leave their initial location before evacuating, they still may not have wilfully made the decision and initiated their evacuation. Additionally, for those joining the queue from initial positions elsewhere in the function room this assumption may result in an overestimation of pre-evacuation time, given that they actually started their evacuation movement some time earlier. Given the short distances involved, and the times taken by 
some individuals who were picked up on more than one camera it is estimated that this overestimation of pre-evacuation time may be in the region of 5-15 seconds. Assuming that the time to join the queue can be used as an estimate of pre-evacuation time, the pre-evacuation time distribution for the function room is shown in Figure 4.

Figure 4 illustrates that almost one third of the population of the function room started their evacuation within the first 20 seconds of the alarm. This comprised almost entirely those occupants originally on the dance floor, directly adjacent to the emergency exit. The persistence of the DJ in announcing the need to evacuate and his repeated announcements urging occupants to leave quietly and calmly seemed to have the desired effect by encouraging those occupants to remain in place and subsequently evacuate. Figure 4 also illustrates that the last occupants joined the queue at 140 seconds, more than 4 minutes prior to the space being totally evacuated.

\section{Flows Final Exit}

As noted above, all occupants in the function room had started their evacuation in less than 140 seconds following the alarm. The total evacuation of the function room took 6 minutes and 34 seconds.

The evacuation of the function room was characterised by the extended flow time through the final exit $(1.2 \mathrm{~m})$. The nature of the timing of this evacuation was such that at the time of the alarm almost half of the occupants of the function room were standing in the vicinity of the final exit which was close to the DJ and the bar.

As noted previously, the first occupants began to flow through the exit 42 seconds after the alarm; from this time until the space was cleared at 394 seconds there was a continuous flow of persons through the exit. The flow during that period was 25.9 people/minute or specific flow of 21.6 people $/ \mathrm{m} / \mathrm{min}$. Figure 5 (solid line) shows the number of occupants remaining in the function room over time. From Figure 5 it is apparent that, after the initial delay, there was a fairly steady flow of occupants through the final exit until about 100 seconds. The flow during this time was 58.8 people/min (specific flow: 49 people $/ \mathrm{m} / \mathrm{min}$ ). Thereafter, from 100 to 200 seconds, the flow reduced to approximately half, i.e. 29.4 people/min (specific flow: $24.5 \mathrm{people} / \mathrm{m} / \mathrm{min}$ ). One of the main reasons for this reduced flow was most certainly the nature of the space into which the occupants were discharging. In this building, the final exit from the function room discharged onto a short path after which time occupants were immediately faced with a grass verge and steps leading up to a raised area behind the building. Many occupants seemed to consider themselves safe once they were in the open air and, having reached a certain point on the steps, did not continue to move away from the building, thus restricting the flow of others from the final exit. On a number of occasions, in the period between 240 and 310 seconds, the actions of males on the steps, clearly under the influence of alcohol brought the flow almost to a standstill. On one occasion a male, attempting to come back down the steps caused the flow to stop as others chatted to him; on another, males were hugging and swaying on the steps and making no attempt to move onwards. Twice during this period a male fell backwards on the steps and was picked up by friends/other evacuees.

The size of the queue which formed at the emergency exit over the duration of the evacuation is also illustrated in Figure 5. This was calculated as the number of people entering the area adjacent to the exit minus a) those leaving the building via the final exit and b) those clearly seen to be leaving the area and moving to other areas of the function room. From Figure 5 it is clear that the size of the queue reduced in the very early stages of the evacuation (0-30 
seconds). This period was characterised by 24 persons leaving the dance floor area and returning to the seating areas in other areas of the function room whilst others (fewer in number) joined the queue. Note that during this period occupants in the immediate vicinity of the final exit, although standing waiting, had not yet started to leave. In the next 30 seconds the queue increased in size as evacuating occupants joined the queue at a rate higher than the discharge through the final exit. From 60 to 140 seconds the queue reduced in size as occupants continued to join but at a lower rate than the discharge from the final exit. It is clear, given the merging of the two series at 140 seconds that all occupants had started their evacuation process at this time and that the remaining 254 seconds of the 394 second evacuation time comprised only the time for remaining occupants to flow through the final exit.

\section{DISCUSSION}

The results and analysis presented above suggests some differences in the characteristics of the evacuations of the lounge bar and the function room. The evacuation time in the lounge bar was characterised by on average longer pre-evacuation times and shorter movement times to exit; the evacuation of the function room was characterised by on average shorter preevacuation times but extended flow times.

The impact of directed voice communications was evident in both areas. In the lounge bar there was little disengagement from pre-alarm activities until the bar manager made an announcement over the PA system at 42 seconds, after which time there was a distinctly visible increase in response activity among the occupants. Many of the occupants in the lounge bar continued to talk/drink until prompted to leave either by the PA announcement or direct instruction from members of staff. In the function room, the cessation of the music, the turning on of lights and the repeated instructions of the DJ ( 8 in total) to leave immediately clearly had an impact with approximately $40 \%$ of the occupants remaining on the dance floor and joining the queue to evacuate via the nearby emergency exit. The live voice communication, in addition to the alarm, is an important feature of this study, and the data suggests that in both spaces this had a significant impact on the pre-evacuation times. The impact of this intervention and other directed actions of staff in such premises should not be underestimated and should be recognised in any fire safety engineering design solution.

It was clear, however, that some occupants took considerable time to disengage from prealarm activities (talking and drinking), despite repeated notifications to evacuate and that others, although disengaging within a relatively short time frame from the alarm, then engaged in other activities that delayed their evacuation, including retrieving their own and others' belongings (mainly coats) and indeed going to the toilet. For those in the function room, in particular, the action of retrieving belongings took some considerable time (on average 50 seconds) as occupants made their way against the crowd back to their original locations. The potential for counter-flows is therefore an important consideration when modelling evacuation and engineering the design of such premises.

Although there were extended pre-evacuation times in the function room, the protracted overall evacuation time was dictated by the flow through the final exit. Many occupants seemed to consider themselves safe once they were in the open air and, having reached a certain point on the steps, did not continue to move away from the building, thus restricting the flow of others from the final exit. It is important to recognise that the exit capacity in the function room exceeded (by $0.15 \mathrm{~m}$ ) that suggested in current regulatory guidance documents 
such as Approved Document B (ADB) [17] for the occupancy levels. However, the specific flow through the final exit, even at its peak was only 49 people $/ \mathrm{m} / \mathrm{min}$ which is $40 \%$ less than the 80 people $/ \mathrm{m} / \mathrm{min}$ assumption which underpins the $5 \mathrm{~mm} /$ person exit requirement in ADB (and hence flow time far exceeded that aimed for as per guidance of $2.5 \mathrm{~min}$ ). Clearly in this respect the final exit did not meet the definition of a final exit as expressed in ADB [17] as 'the termination of an escape route from a building giving direct access to a street, passageway, walkway or open space and sited to ensure the rapid dispersal of persons from the vicinity of the building so that they are no longer in danger from fire and/or smoke". This reinforces the need for designers to ensure that their design decisions extend beyond the final exit from the building to ensure that the space beyond the exit does not have potential to restrict the flow out of the building and for engineers to fully consider the limiting factor in the flow from the building.

Previous studies have indicated that behaviour in such premises is characterised by social norms and normative behaviour. Whilst this was also evident here, with most patrons being generally responsive to, and compliant with, requests and directions given by staff and engaging in orderly behaviour, there was also evidence of situations where alcohol clearly impaired occupants' ability to evacuate. One example was of an obviously intoxicated male who left the dance floor for almost two minutes before initiating his evacuation. There were also examples of individuals hugging, swaying, and indeed falling backwards as they ascended the exterior steps. This is an important observation that may have implications for design and modelling and indeed management of evacuation in such premises, particularly those which include basements.

\section{CONCLUDING REMARKS}

As noted previously, an understanding of the behaviour of individuals and groups and reliable and accurate data on the components of the engineering timeline, are essential for engineering design and computational modelling. To date our understanding of response behaviourin licensed premises, including bars/clubs, has been restricted to that gleaned from interviews/surveys of survivors of real fires after the event but these studies, by their very nature, have been unable to shed light on potential pre-evacuation and movement times.

The analysis of an unannounced evacuation of the licensed premises, presented in this paper, is the first of its kind in the published literature. The analysis presented has provided not only important data with respect to the components of the evacuation time in premises such as bars/clubs where alcohol is being served, but also information on evacuation behaviours which have important implications for the engineering design and indeed management of such premises. 


\section{REFERENCES}

1. National Fire Protection Association. Cocoanut Grove Nightclub Fire Report, Boston, National Fire Protection Association, 1943.

2. Best RL.Reconstruction of a Tragedy: The Beverly Hills Supper Club Fire, Southgate, Kentucky, May 28, 1977. An analysis of the Development and Spread of Fire from the Room of Origin to the Cabaret Room, Boston, National Fire Protection Association.

3. Keene R. Tribunal of inquiry on the fire at the Stardust, Artane, Dublin on 14 February 1981. Government publications. P1.853. Dublin: Stationery Office, 1982.

4. Levy CJ. Toll Stirs Anger in Russian Nightclub Fire. New York Times, [online] 5 December, $2009 . \quad$ Available at: $<$ http://www.nytimes.com/2009/12/06/world/europe/06russia.html?_r=0 $\geq$ [Accessed 15 July 2015].

5. Grosshandler WL, Bryner NP, Madryskowski D, and Kuntz K. Report of the Technical Investigation of The Station Nightclub Fire (NIST NCSTAR 2), Volume 1 and Volume 2, National Institute of Standards and Technology, USA, 2005.

6. Duval RF. NFPA Case Study: Nightclub Fires, National Fire Protection Association, 2006.

7. Duffy G. Scores killed in nightclub fire in Santa Maria, Brazil. BBC, [online] 28 January, 2003. Available at: http://www.bbc.co.uk/news/world-21220308 [Accessed 15 July 2015].

8. Johnson NR. Panic and the Breakdown of Social Order: Popular Myth, Social Theory, Empirical Evidence. Sociological Focus, 1987; 20, pp. 171-83.

9. Feinberg WE, Norris RJ. Primary Group Size and Fatality Risk in a Fire Disaster. Pp. 1122 In Human Behaviour in Fire, Understanding Human Behaviour for Better Fire Safety Design, Second International Symposium, 2001. London: Interscience.

10. Johnson, NR, Feinberg WE, and Johnson DM. Microstructure and panic: The impact of social bonds on individual action in collective flight from the Beverly Hills Supper Club Fire. In Dynes RR, \& Tierney KJ (Eds.) Disasters, collective behaviour and social organization (pp. 168-189). Newark: University of Delaware Press, 1994.

11. Aguirre BE, Torres MR, Gill KB and Hotchkiss HL. Normative collective behaviour in the station building fire. Social Science Quarterly, 2011; 92(1), pp. 100-118.

12. Fahy RF, Proulx G, and Flynn J. The Station Nightclub Fire - An analysis of witness statements, Fire Safety Science Proceedings of the Tenth International Symposium, International Association Fire Safety Science, 2011: pp 197-209.

13. British Standards Institution. PD 7974-6:2004, The application of fire safety engineering principles to fire safety design of buildings. Human factors. Life safety strategies. Occupant Evacuation, Behaviour and Condition (Sub-system 6), British Standards Institution, London, UK., 2004.

14. Gwynne SMV, Boyce KE. Chapter 64 Engineering Data in Hurley MJ, Gottuk DT, Hall Jr, JR, Harada K, Kuligowski ED, Puchovsky M, Torero JL, Watts Jr, JM, Wieczorek CJ (Eds.) SFPE Handbook of Fire Protection Engineering, 5th Edition, Springer. 2015 ISBN 978-1-4939-2565-0.

15. Bradley G (1997), The Characterisation and Escape Behaviour of Occupants of Licensed Premises, Internal Report, University of Ulster.

16. Galea ER, Sharp G, Sauter M, Deere S, Filippidis L. Investigating the Impact of Culture on Evacuation Behaviour - A Polish Data Set, Proceedings of 5th International Symposium Human Behaviour in Fire, Downing College Cambridge 19-21 September 2012, Interscience Communications, pp 62-73.

17. Approved Document B, The Building Regulations 2010, Volume 2 - Buildings Other than Dwelling Houses, HM Government, 2006. 


\section{Table 1 Breakdown of Occupants by Location}

\begin{tabular}{lcccc} 
Location & $\begin{array}{l}\text { Males } \\
(\%)\end{array}$ & $\begin{array}{l}\text { Female } \\
(\%)\end{array}$ & Total & $\begin{array}{l}\text { Evacuation } \\
\text { time }(\mathrm{sec})\end{array}$ \\
\hline Function & 94 & 58 & 152 & 394 \\
Room & $(61.8)$ & $(38.2)$ & & \\
Lounge & 37 & 35 & 72 & 199 \\
Bar & $(51.4)$ & $(48.6)$ & &
\end{tabular}

$\begin{array}{lllll}\text { Public Bar } & 15^{*} & 0 & 15^{*} & 120^{*}\end{array}$

*estimates by bar manager - breakdown by sex unknown 
Table 2 Activities Observed during Pre-Evacuation - Lounge Bar

Activities

Percentage of Sample*

Collected belongings for others/self

30.0

Put on over Garment

27.5

Returned to talk

25.0

Returned to drinking

22.5

Waiting on Others

15.0

Visited Toilet

10.0

Moved to instruct other to leave

5.0

*Note: percentages do not add to 100 since some occupants completed multiple activities. 


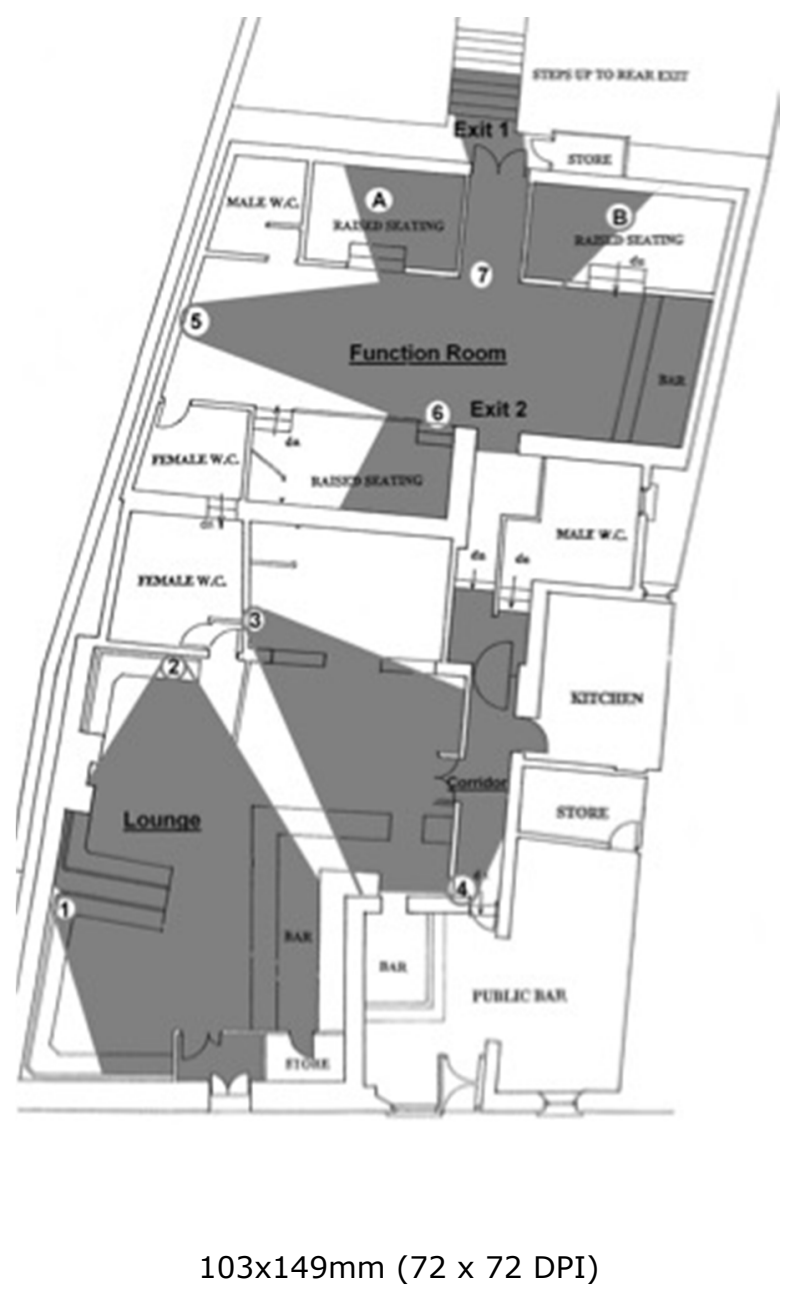

39

40

41

42

43

44

45

46

47

48

49

50

51

52

53

54

55

56

57

58

59

60

http://mc.manuscriptcentral.com/fam 


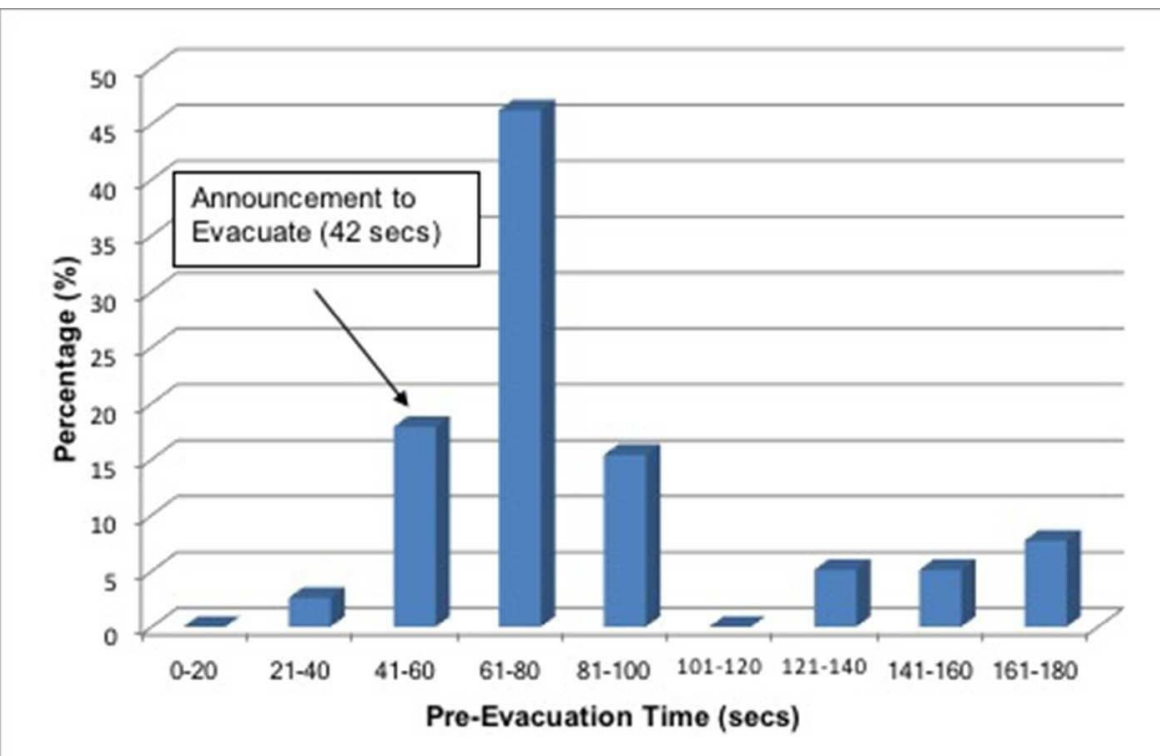

$159 \times 104 \mathrm{~mm}(72 \times 72 \mathrm{DPI})$ 


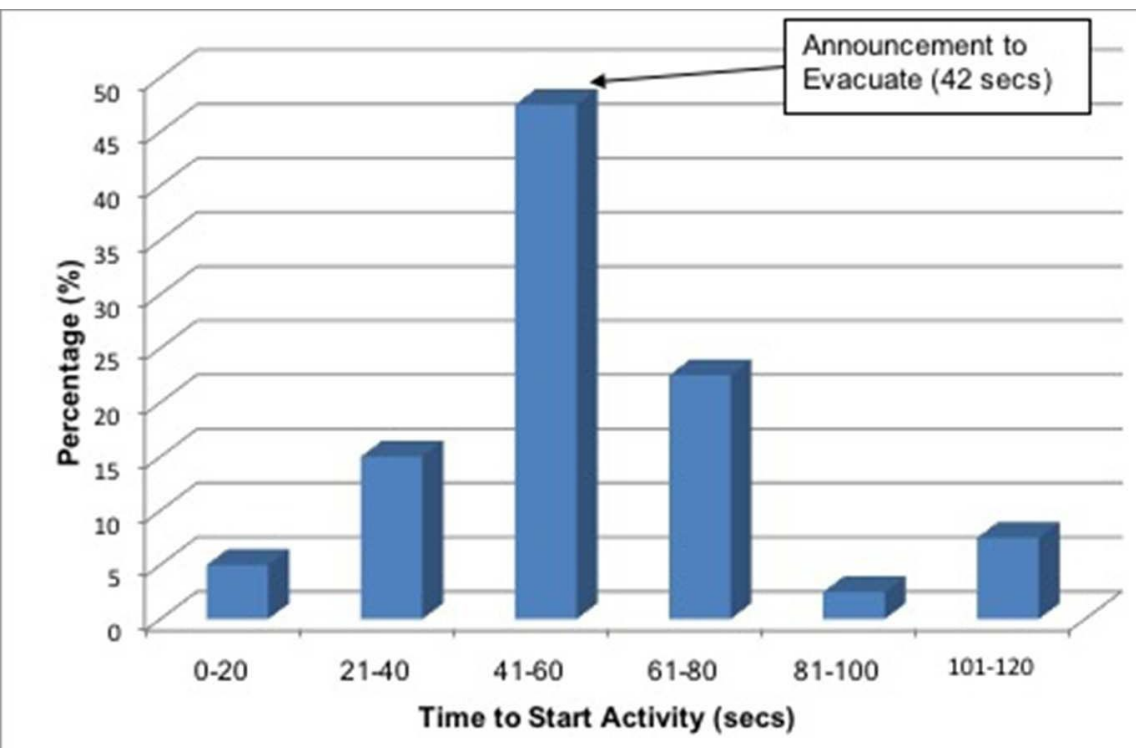

$159 \times 104 \mathrm{~mm}(72 \times 72 \mathrm{DPI})$ 


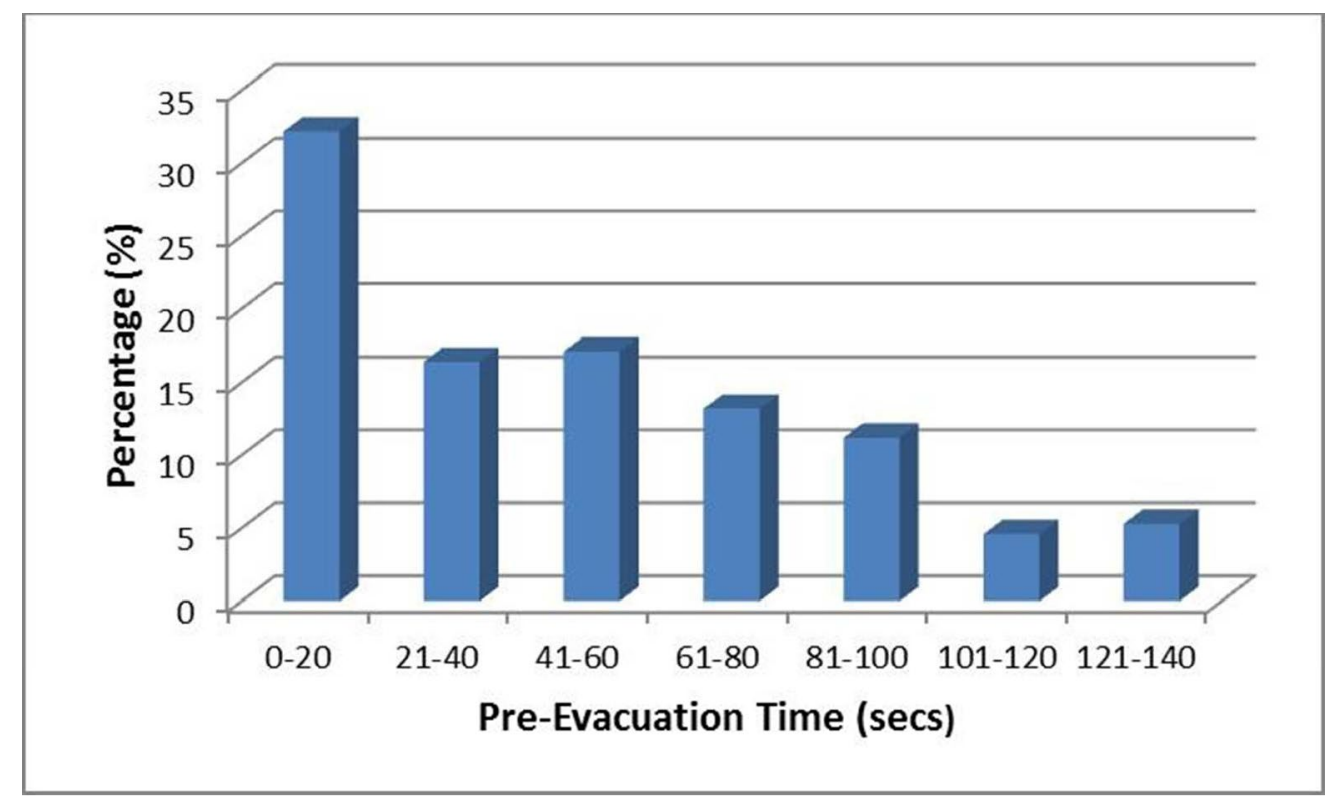

$127 \times 76 \mathrm{~mm}(150 \times 150 \mathrm{DPI})$ 


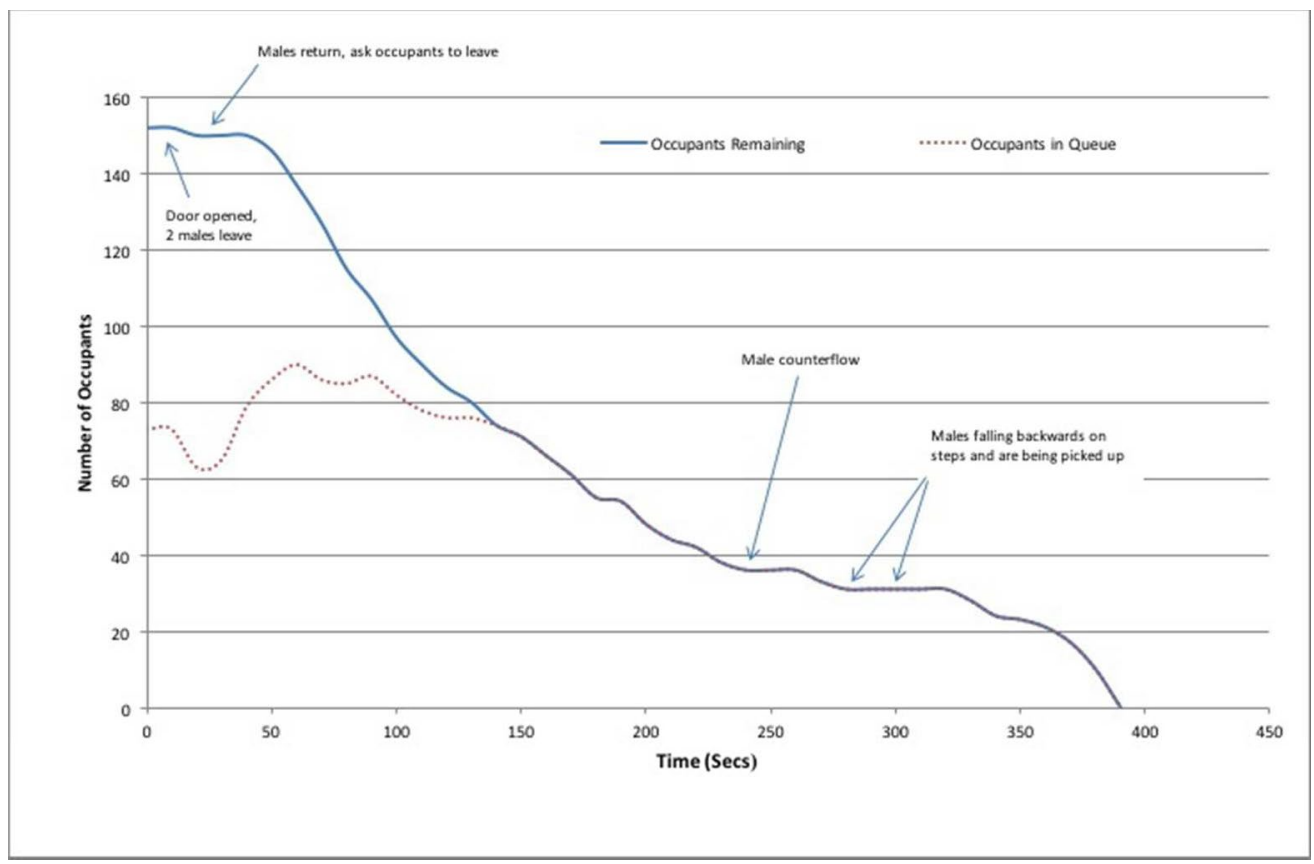

$258 \times 168 \mathrm{~mm}(72 \times 72 \mathrm{DPI})$

http://mc.manuscriptcentral.com/fam 